\title{
Fragile X Mental Retardation Protein Is Associated with Translating Polyribosomes in Neuronal Cells
}

\author{
Giovanni Stefani, Claire E. Fraser, Jennifer C. Darnell, and Robert B. Darnell \\ Howard Hughes Medical Institute and Laboratory of Molecular Neuro-Oncology, The Rockefeller University, New York, New York 10021
}

Fragile X mental retardation protein (FMRP) is an RNA binding protein encoded by the gene FMR1, whose expression is impaired in patients with fragile $\mathrm{X}$ mental retardation. The association of FMRP with polyribosomes in non-neural cell lines has previously suggested that FMRP is involved in translational regulation. However, the relevance of these studies to neuronal function has been questioned by the finding that FMRP in brain is not associated with polyribosomes, but is part of small ribonucleo-protein complexes that do not appear to include ribosomes. Here we optimize methods to analyze brain polyribosomes, allowing us to definitively demonstrate that FMRP forms complexes with cortical brain polyribosomes. Moreover, we demonstrate in neuroblastoma cells that the FMRP-polyribosome complexes are sensitive to puromycin, a drug that targets actively translating ribosomes. These data indicate that FMRP associates with functional polyribosomes in neurons.

Key words: cortex; RNA; translation; fragile-X mental retardation; polyribosome; puromycin

\section{Introduction}

Fragile $\mathrm{X}$ mental retardation is a frequent genetic cause of mental retardation, affecting $\sim 1$ in 4000 males. The syndrome most frequently results from transcriptional silencing of the Fmrl gene caused by methylation of the expanded CGG repeats in the $5^{\prime}$ untranslated region (for review, see O'Donnell and Warren, 2002; Jin and Warren, 2003). Fragile X Mental Retardation Protein (FMRP), the protein encoded by Fmr1, is an RNA binding protein harboring two KH-type and one RGG-type RNA binding motifs (Ashley et al., 1993; Siomi et al., 1993). Studies aimed at characterizing RNA sequences specifically bound by FMRP have shown that its RGG domain binds RNAs containing G-quartet motifs (Darnell et al., 2001; Schaeffer et al., 2001; Ramos et al., 2003); this structural motif has been found in several RNAs whose expression or localization is affected by the absence of FMRP (Brown et al., 2001; Miyashiro et al., 2003; Todd et al., 2003).

Converging lines of evidence support a role of FMRP in translational control. FMRP is found associated with polyribosomes in various non-neuronal cell lines (Eberhart et al., 1996; Khandjian et al., 1996; Corbin et al., 1997; Feng et al., 1997a), and in human cell lines derived from Fragile X syndrome patients, the abundance of a set of mRNAs in the polyribosomal fraction is altered (Brown et al., 2001). The Drosophila ortholog of FMRP, dFXR, has been shown to repress the expression of futsch at the translational level (Zhang et al., 2001). Finally, the ability of FMRP to act as a translational repressor of reporter constructs has been demonstrated in vitro and in transfected cells (Laggerbauer et al., 2001; Li et al., 2001; Mazroui et al., 2002). It has been suggested

Received April 21, 2004; revised July 16, 2004; accepted July 8, 2004.

This work was supported by National Institutes of Health Grants R01 NS34389, NS40955 (G.S., R.B.D.), R01 HD40647 (J.C.D.), and MSTP-GM07749 (C.E.F.). R.B.D. is an investigator of the Howard Hughes Medical Institute. We thank Taesun Eom for help in performing experiments in primary neurons and members of the laboratory for helpful discussions and critical reading of this manuscript.

Correspondence should be addressed to Dr. Robert B. Darnell, Laboratory of Molecular Neuro-Oncology, The Rockefeller University, Box 226, 1230 York Avenue, New York, NY 10021. E-mail: darnelr@rockefeller.edu. DOI:10.1523/JNEUROSCI.2306-04.2004

Copyright $\odot 2004$ Society for Neuroscience $\quad$ 0270-6474/04/247272-05\$15.00/0 that the loss of proper regulation of translation of FMRP target mRNAs underlies the morphological and functional abnormalities observed at some synapses of Fmr1-null mice (Huber et al., 2002; O'Donnell and Warren, 2002).

These observations have been tempered by the question of whether they are relevant to FMRP function in the mammalian brain. To date, no analysis has definitively shown the presence of FMRP on polyribosomes from brain, primarily because of technical difficulties in sedimentation studies using CNS tissue. However, a recent study reported that FMRP is in fact not associated with polyribosomes in brain extracts, but rather that it cosediments with the $80 \mathrm{~S}$ ribosome and with heterogeneous complexes of smaller size (Zalfa et al., 2003).

In addition to this contradiction between tissue culture and in vivo tissue studies regarding FMRP polysome association, the molecular mechanism through which FMRP might modulate the expression of its target mRNAs is unknown. Recent evidence of an association of dFXR and FMRP with components of the RNAinduced silencing complex (RISC) suggests a mechanism involving micro RNA (miRNA)-mediated gene silencing (Caudy et al., 2002; Ishizuka et al., 2002; Jin et al., 2004), and have seemed consistent with a role for FMRP in regulating translation. However, even tissue-culture studies have failed to convincingly show whether FMRP associates with actively translating polyribosomes or with translationally arrested ribosome-associated messenger ribonucleo-protein complexes (RNPs) of the sort that have been suggested to be involved in miRNA-mediated mechanisms (Olsen and Ambros, 1999; Seggerson et al., 2002). In tissue-culture studies, the FMRP-polyribosome association has been disrupted by treatment with EDTA (Eberhart et al., 1996; Khandjian et al., 1996) or with nonspecific metabolic poisons such as sodium azide (Feng et al., 1997a; Ceman et al., 2003), but it is unknown whether the FMRP-polyribosome association can be disrupted with an agent such as puromycin that specifically disrupts active translating ribosomes.

In the present study we describe a reliable technique for the 
analysis of polyribosomes from cerebral cortical extracts of postnatal and adult mice on sucrose density gradients. Our analysis demonstrates that FMRP cosediments with polyribosomes in brain extracts, consistent with observations obtained in cell lines derived from other tissues. Moreover, we find that treatment of neuroblastoma cells in culture with puromycin disrupts FMRP association with polyribosomes. These results demonstrate that FMRP is associated with functional polyribosomes in neuronal cells.

\section{Materials and Methods}

Polyribosome analysis. Polyribosomes from cortex were analyzed as follows. CD1 mice at various ages were killed by decapitation after anesthesia with chloroform. The brain was removed from the skull and placed in ice-cold HEPES HBSS (HHBSS: $1 \times$ Hank's basal salt solution, $2.5 \mathrm{~mm}$ HEPES-KOH, pH 7.4, $35 \mathrm{~mm}$ glucose, and $4 \mathrm{~mm} \mathrm{NaHCO}_{3}$ ) containing $100 \mu \mathrm{g} / \mathrm{ml}$ of cycloheximide. From this point on, the material was kept ice-cold or at $4^{\circ} \mathrm{C}$ throughout the preparation. Each cerebral cortex was dissected free of cerebellum, brainstem, mesencephalon, diencephalon, basal ganglia, and much of the underlying white matter. The HHBSS was replaced with $1.2 \mathrm{ml}$ of homogenization buffer per cortex (homogenization buffer: $10 \mathrm{~mm}$ HEPES-KOH, pH 7.4, $150 \mathrm{~mm} \mathrm{KCl,} 5 \mathrm{~mm} \mathrm{MgCl}_{2}$, and $0.5 \mathrm{~mm}$ DTT) containing protease and RNase inhibitors (complete EDTA-free from Roche Products, Hertfordshire, UK and Rnasin from Promega, Madison, WI). Tissues were homogenized with 12 strokes at $900 \mathrm{rpm}$ in a motor-driven glass-Teflon homogenizer. The homogenized material was spun at $2000 \times g, 10 \mathrm{~min}$, and NP-40 was added to the supernatant (S1) to a final concentration of $0.3 \%$ or $1 \% \mathrm{v} / \mathrm{v}$. After $5 \mathrm{~min}$ of incubation on ice, the material was spun at $20,000 \times g$ for $10 \mathrm{~min}$, and the supernatant (S2) was loaded onto $20-50 \% \mathrm{w} / \mathrm{w}$ linear density gradient of sucrose in $10 \mathrm{~mm}$ HEPES-KOH, pH 7.4, $150 \mathrm{~mm} \mathrm{KCl,} 5 \mathrm{~mm} \mathrm{MgCl}$, or $30 \mathrm{~mm}$ EDTA where indicated. In the indicated samples, EDTA was added to S2 to a final $30 \mathrm{~mm}$ concentration before loading on the gradient. Material obtained from one cortex or one-half cortex was loaded onto each gradient. The gradients were centrifuged at $40,000 \times g$ for $2 \mathrm{hr}$ at $4^{\circ} \mathrm{C}$ in a Beckman Instruments (Fullerton, CA) SW 41 rotor. Fractions of 0.5 or $0.75 \mathrm{ml}$ volume were collected with continuous monitoring at $254 \mathrm{~nm}$ using an ISCO UA-6 UV detector. For the RNase experiments, before centrifugation, the S2 fraction was incubated with $1000 \mathrm{U} / \mathrm{ml}$ RNase T1 (Ambion, Austin, TX) and $44 \mathrm{U} / \mathrm{ml}$ RNase A (United States Biochemical, Cleveland, $\mathrm{OH}$ ) for $10 \mathrm{~min}$ at room temperature.

The same procedure was used for the analysis of polyribosomes extracted from cells in culture. A postmitochondrial extract was obtained by lysis of $1 \times 10^{7} \mathrm{~N} 2$ a cells (American Type Culture Collection, Manassas, VA) or primary cortical neurons from seven 10 -cm-diameter dishes in $1 \mathrm{ml}$ of the following buffer: $20 \mathrm{~mm}$ HEPES-KOH, pH 7.4, 10 $\mathrm{mm} \mathrm{KCl}, 5 \mathrm{~mm} \mathrm{MgCl} 2,0.3 \%$ NP-40, $0.5 \mathrm{~mm}$ dithiothreitol, $40 \mathrm{U} / \mathrm{ml}$ Rnasin (Promega), and complete protease cocktail (Roche). The salt concentration was adjusted to $150 \mathrm{~mm}$ with $1 \mathrm{M} \mathrm{KCl}$, and the lysate was spun $12,000 \times g, 20 \mathrm{~min}$ at $4^{\circ} \mathrm{C}$. The resulting supernatant was loaded on sucrose gradients as described above.

Western blot analysis. The proteins contained in each fraction of the sucrose gradients were TCA-precipitated and analyzed by Western blot using anti-FMRP monoclonal antibody diluted 1:1000 (1C3; Chemicon, Temecula, CA), anti-S6 ribosomal protein (Cell Signaling Technology, Beverly, MA), anti-P0 ribosomal protein (a kind gift from Dr. Tan, Scripps Institute), and anti-poly(A) binding protein (PABP) (10E10; Immunoquest). Signal was detected by chemiluminescence. The membranes were exposed on Biomax MR film (Eastman Kodak, Rochester, NY) and to the digital camera of a Versadoc Imaging System (Bio-Rad, Hercules, CA).

Culture of Neuro-2a cells. Neuro-2A cells, a mouse neuroblastoma line (catalog \#CCL-131; American Type Culture Collection) were grown to $80 \%$ confluence in $15-\mathrm{cm}$-diameter dishes in 10\% FBS-DMEM with penicillin-streptomycin.

Pharmacological treatments of cells. Cells in culture were treated with $0.35 \mathrm{~mm}$ cycloheximide (Sigma, St. Louis, MO) for $10 \mathrm{~min}$ or with $1 \mathrm{~mm}$ puromycin (Sigma) for $3 \mathrm{hr}$ before lysis, as described. Cycloheximide was dissolved in methanol, and puromycin was dissolved in water.

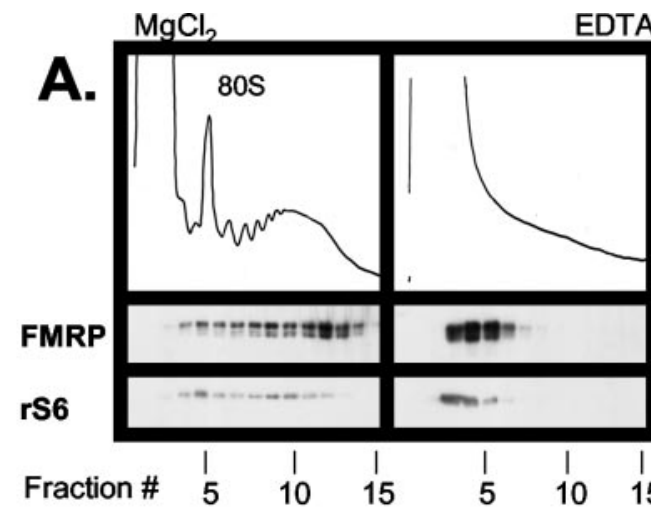

\section{Extratcs from 9 days old mice}

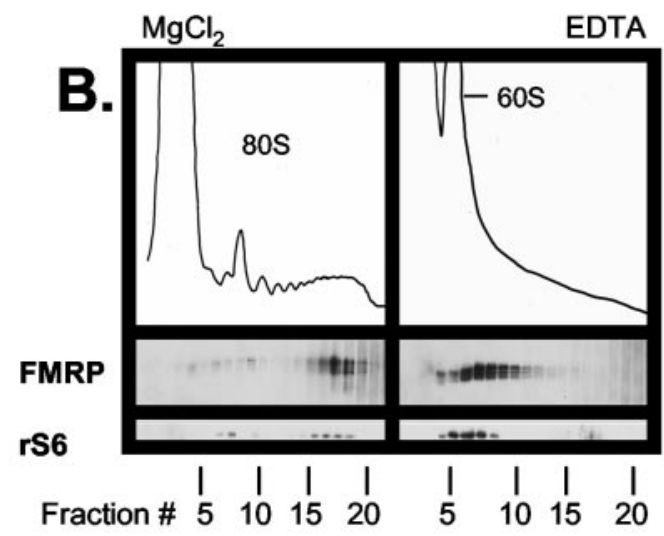

Extracts
from 5
months
old mice

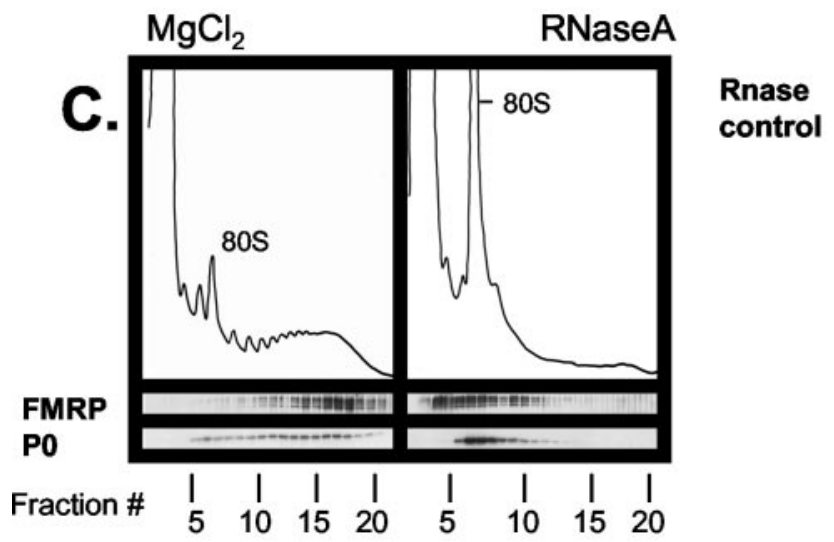

Figure 1. Association of FMRP with polyribosomes in extracts from brain cortex of mice at different ages. Cytoplasmic extracts were prepared from brain cortices of 9-d-old ( $A$ ), 5 -monthold $(B)$, and 53 -d-old $(C)$ mice and centrifuged on a $20-50 \% \mathrm{w} / \mathrm{w}$ linear sucrose gradient. Fractions were collected and analyzed by Western blot with antibodies against FMRP and ribosomal 56 protein ( $(56)$. Extracts treated with $30 \mathrm{~mm}$ EDTA or RNase (C) were analyzed in parallel. Fractions from the top to the bottom of the gradient are shown from left to right. The positions of the $80 \mathrm{~S}$ ribosome monomer and $60 \mathrm{~S}$ subunit are indicated.

\section{Results}

FMRP is associated with polysomes in brain

To study the pattern of sedimentation of FMRP extracted from mouse brain, we fractionated lysates obtained from cortex on linear sucrose density gradients. We found that the removal of the white matter underlying the cortex was required to obtain clean $\mathrm{OD}_{254}$ profiles. FMRP sedimented in complexes widely overlapping with the distribution of ribosomal protein S6 in cortical extracts from young animals (9-d-old) (Fig. 1A). Treatment of the lysate with $30 \mathrm{~mm}$ EDTA before the beginning of the fraction- 
ation, which entirely disrupts polyribosomes by causing the dissociation of the large and small ribosomal subunits, also disrupted the FMRP complexes into smaller size complexes that sedimented at $\sim 60 \mathrm{~S}$ (Fig. $1 \mathrm{~A}$, right panel).

The same pattern of FMRP sedimentation was observed on linear density gradients prepared from brain extracts of animals of different ages. Figure $1 B$ shows that in adult animals (5-months-old) FMRP is part of complexes that sediment with polysomes and are disrupted by treatment with EDTA (Fig. $1 B$, right panel).

To examine whether the cosedimentation of FMRP with polysomes in the brain was RNA-dependent, extracts were treated with RNase A. This treatment resulted in complete disruption of polysomes, as shown by the shift of ribosomal protein $\mathrm{P} 0$, and also shifted FMRP to the lighter fractions of the gradient (Fig. $1 C)$. These results demonstrate that the large FMRP complexes present in the brain are dependent on the presence of RNA, in agreement with previous observations in non-neuronal cell lines and consistent with the association of FMRP with polyribosomes (Eberhart et al., 1996; Ceman et al., 2003).

One variable used in previous polysome profiles from brain has been the presence (Bagni et al., 2000) or absence of ionic detergent such as deoxycholate (Bagni et al., 2000; Zalfa et al., 2003). To rule out the possibility that the observed fast velocity of sedimentation of FMRP might relate to the presence or absence of detergents, we analyzed gradients of brain extracts prepared in the presence of deoxycholate or in the presence of no detergent. After elimination of the insoluble material with a 20,000 $\times g$ centrifugation step, we obtained clearly discernible polysome peaks in sucrose gradients (Fig. $2 \mathrm{~A}$ ). In agreement with our previous results, FMRP cosediments with polysomes in this preparation, eliminating the possibility of technical artifacts caused by the presence of detergents in the extract. Conversely, we find that FMRP association with polyribosomes is completely disrupted by the presence of deoxycholate (Fig. $2 B$ ). These results demonstrate that FMRP is associated with polyribosomes in the brain.

\section{Inhibition of translation disrupts FMRP complexes}

FMRP has been shown to be associated with translating polyribosomes in a number of non-neuronal cell lines, as assessed by treatment with agents such as sodium fluoride and sodium azide that have pleiotropic actions (Eberhart et al., 1996; Khandjian et al., 1996; Corbin et al., 1997; Feng et al., 1997a; Ceman et al., 2003). To assess whether FMRP is associated with actively translating polyribosomes in cells of neuronal lineage, we treated Neuro-2a cells, a murine neuroblastoma cell line, with the translational inhibitor puromycin. Puromycin is an analog of aminoacyl transfer RNA that binds to the acceptor site of the ribosome, blocking elongation and causing premature release of the growing polypeptide chain (Davis et al., 1974). Therefore, the drug specifically targets actively translating polysomes. FMRP cosediments with the larger polyribosomes in Neuro-2A cells treated with cycloheximide (Fig. 3, top panel), as observed in the brain. After treatment of Neuro-2A cells with $1 \mathrm{~mm}$ puromycin for $3 \mathrm{hr}$, virtually all polyribosomes containing multiple (i.e., $>4-6$ ) ribosomes were fully disrupted, whereas the peak corresponding to the $80 \mathrm{~S}$ ribosome monomer was markedly increased, as judged by the $\mathrm{OD}_{254}$ profile and the Western blot for ribosomal protein S6 (Fig. 3, middle panel). Under these conditions, the sedimentation of FMRP shifts from fractions harboring large polyribosomes (more than six ribosomes) to less dense fractions. These FMRP-containing fractions present after puromycin treatment correspond either to nontranslating monosome-size particles or to residual polyribosomes containing 2-4 ribosomes (Fig. 3,

\section{A. No detergent}

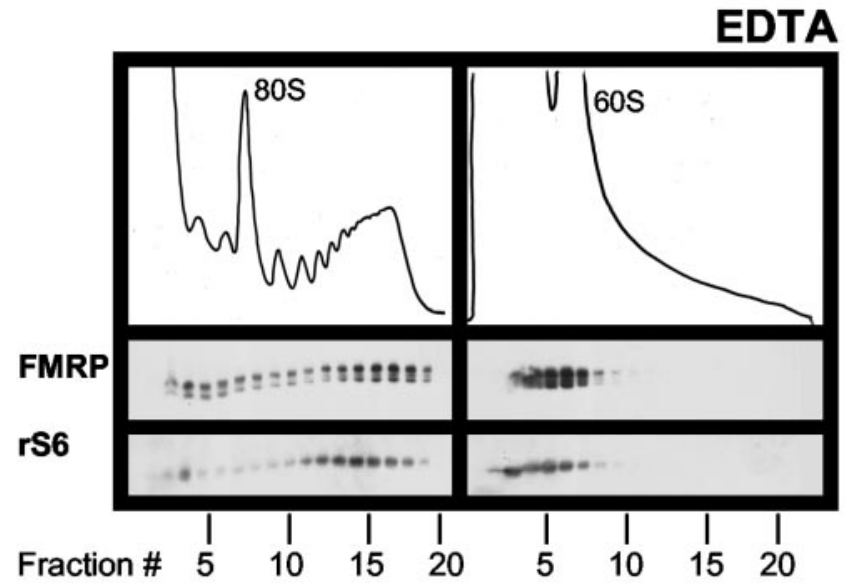

B.

$1 \%$ NP40

$1 \% \quad$ NP40

$0.5 \%$ DOC

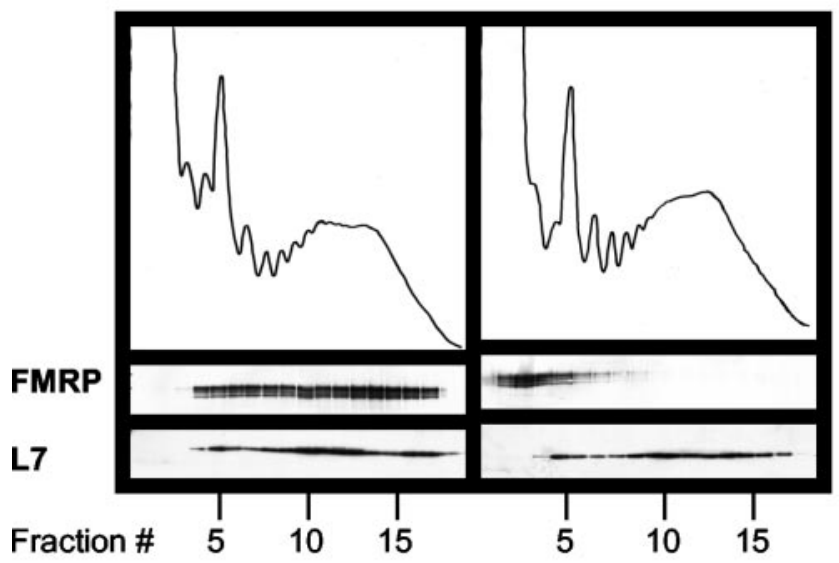

Figure 2. Effects of treatment with different detergents on the association of FMRP with polyribosomes. $A$, Cortical extracts were prepared from 8-d-old mice in complete absence of detergent and analyzed as in Figure 1. $B$, Treatment with deoxycholic acid disrupts the interaction of FMRP with polyribosomes. Cytoplasmic extracts from mouse brain cortex were treated with $1 \%$ NP-40 (left panel) or 1\% NP-40 and $0.5 \%$ deoxycholic acid (right panel). Subsequently, the extracts were fractionated on a $20-50 \% \mathrm{w} / \mathrm{w}$ sucrose linear density gradient. Fractions were collected and analyzed by Western blot using anti-FMRP (IC3) and anti-L7 antibodies.

middle panel). Ribosomal protein S6, PABP, and ribosomal protein L7 shift to smaller fractions, mostly corresponding to $80 \mathrm{~S}$ ribosomal monomers and $60 \mathrm{~S}$ large subunits. The complete disruption of polyribosomes achieved with $30 \mathrm{~mm}$ EDTA results in a further reduction of the size of FMRP complexes to $\sim 60 \mathrm{~S}$, as previously described (Fig. 3, bottom panel) (Eberhart et al., 1996; Khandjian et al., 1996). A similar shift of the size of the FMRP complexes was observed in primary cortical neurons after treatment with puromycin (data not shown). These results demonstrate that FMRP is associated with translating ribosomes in neuronal cells.

\section{Discussion}

We provide definitive evidence that FMRP is associated with polyribosomes in mammalian brain. We have optimized a reli- 


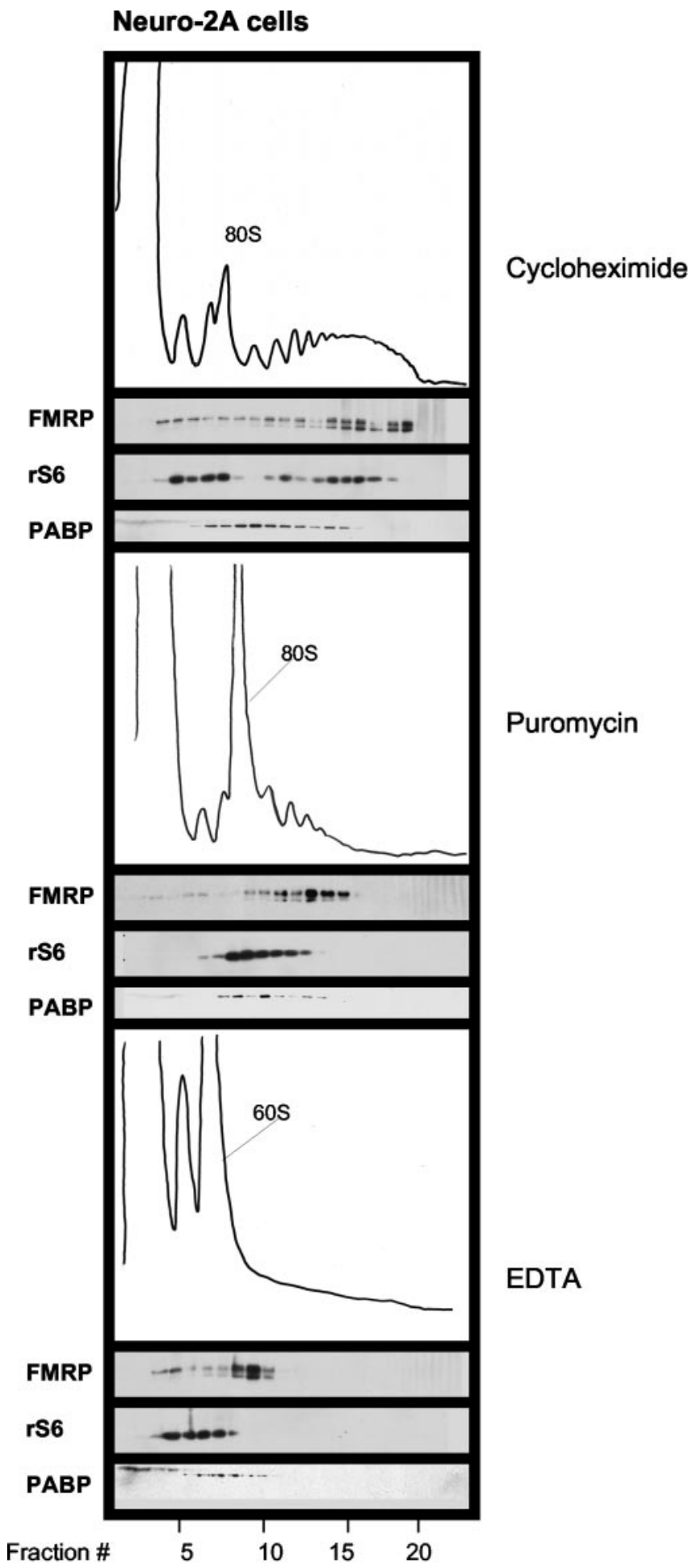

Figure 3. Association of FMRP with translating polyribosomes. Cytoplasmic extracts were prepared from Neuro-2a cells. Cells were treated with $0.35 \mathrm{~mm}$ cycloheximide for $10 \mathrm{~min}$ or with $1 \mathrm{~mm}$ puromycin for $3 \mathrm{hr}$ in the culture medium before lysis. The extracts were analyzed on sucrose density gradients as in Figure 1.

able procedure for the analysis of polyribosomes from differentiated neural tissues, based on the dissection of cerebral cortex free of most of the underlying white matter, followed by homogenization and lysis in mild conditions that preserve the interaction between FMRP and polyribosomes. We reproducibly observed EDTA and RNase-sensitive association of FMRP with polyribosomes in extracts from cerebral cortex from young and adult animals (Figs. 1, 2). Furthermore, we demonstrate that the complexes formed by FMRP with polyribosomes are translationally active in neuronal cells, because treatment with puromycin sufficient for disruption of polyribosomes decreases the rate of sedimentation of FMRP (Fig. 3).

FMRP is widely expressed, with highest expression observed in brain and testis (Abitbol et al., 1993; Devys et al., 1993). Despite the essentially ubiquitous distribution, the human syndrome caused by the absence of FMRP is most notably characterized by cognitive impairments (O'Donnell and Warren, 2002). Therefore, a detailed understanding of FMRP biology in the cerebral cortex is of great interest. Association of FMRP with polyribosomes has been described in non-neuronal cell lines, but contradictory reports exist in the literature about the existence of such interaction in neural tissues. One previous report has suggested a possible association of FMRP with polyribosomes in neural tissue (Feng et al., 1997b). However, the evidence presented was not conclusive, in part because the absence of an absorbance profile makes the integrity and purity of the polyribosomes difficult to assess. In contrast, a recent report suggests that FMRP is not associated with polyribosomes specifically in mouse brain, but instead cosediments with RNPs smaller than a single ribosome (Zalfa et al., 2003). The results presented in this study definitively demonstrate that FMRP cosediments with polyribosomes purified from cerebral cortex. The purity of the polyribosomes from cortex is comparable to preparations from cultured cells, as judged by absorbance profiles.

Although the fast sedimentation rate of FMRP and its sensitivity to EDTA and RNase are highly suggestive of an interaction between FMRP and translating polyribosomes, other interpretations cannot be ruled out a priori. Krichevsky and Kosik (2001) have reported evidence for large molecular weight RNP granules in neurons. However, this data was obtained from primary neuronal cultures, and no such granules were seen in cells grown for $3 \mathrm{~d}$ in vitro (only after $7 \mathrm{~d}$ in vitro), suggesting a phenomenon closely related to culture conditions. In the current work, we see no evidence for such RNP granules on A260 profiles of either young or adult mouse brain. In other studies, FMRP has been reported in large cytoplasmic complexes similar to stress granules in tissue culture after various treatments (Mazroui et al., 2002). Past studies suggested an association of FMRP with actively translating polyribosomes in lymphoblastoid cell lines (Feng et al., 1997a; Ceman et al., 2003). These observations were nonetheless inconclusive because they were based on treatment of cells with the metabolic poisons sodium azide or sodium fluoride, which target a wide range of cellular functions in addition to initiation of translation.

We addressed the functional association of FMRP with polyribosomes by specifically disrupting actively translating polyribosomes with puromycin. Disruption of polyribosomes induced by puromycin was accompanied by a reduction of the sedimentation rate of FMRP, demonstrating that the majority of polyribosomes complexed with FMRP are actively translating. Therefore our results suggest a mechanism of translational regulation by FMRP that does not preclude the loading of ribosomes on mRNA and modulates some step of translation subsequent to initiation.

The association of FMRP with actively translating polysomes suggests that the protein may itself play a role in translational regulation. Previous studies have suggested that FMRP may promote mRNA translation (Brown et al., 2001; Miyashiro et al., 2003; Todd et al., 2003). Although in principle an association with actively translating polyribosomes might be consistent with 
a positive role on translation, a number of reports also suggest that FMRP may inhibit the translation of its target RNAs (Laggerbauer et al., 2001; Li et al., 2001; Zhang et al., 2001; Mazroui et al., 2002). Interestingly, whereas puromycin clearly disrupts large FMRP-polyribosome complexes, FMRP still cosediments with the largest remaining polyribosomes containing three to four ribosomes rather than with the much more prominent peak of monomeric ribosomes (Fig. 3). The less than complete shift of FMRP may be consistent with relative translational inhibition of some FMRP-associated transcripts. The association of FMRP with "stalled" polyribosomes has been shown previously to correlate with phosphorylation in non-neuronal cells treated with sodium azide (Ceman et al., 2003). Although unusual, examples of translational repression of mRNAs associated with polyribosomes have been reported. Hacl mRNA expression is regulated on translationally stalled polyribosomes (Chapman and Walter, 1997). Translationally suppressed nanos mRNA is associated with puromycin-sensitive polyribosomes in Drosophila, and is subject to translational runoff in vitro (Clark et al., 2000) Moreover, it has been reported that $l i n-14$ and $l i n-28$ mRNAs, whose translation is blocked by miRNA lin-4, are nonetheless found in the polyribosomal fraction (Olsen and Ambros, 1999; Seggerson et al., 2002). Because FMRP interacts with miRNAs and with members of the Argonaute protein family, it is possible that FMRP modulates the rate of elongation or termination through a mechanism implicating miRNAs (Caudy et al., 2002; Ishizuka et al., 2002; Jin et al., 2004). By modulating the efficiency of translation of mRNAs that are fully engaged in polyribosomal complexes, FMRP might be suitable to mediate particularly rapid and reversible regulatory events, consistent with its proposed role in the regulation of protein synthesis-dependent synaptic plasticity (Huber et al., 2002).

\section{References}

Abitbol M, Menini C, Delezoide AL, Rhyner T, Vekemans M, Mallet J (1993) Nucleus basalis magnocellularis and hippocampus are the major sites of FMR-1 expression in the human fetal brain. Nat Genet 4:147-153.

Ashley Jr CT, Wilkinson KD, Reines D, Warren ST (1993) FMR1 protein: conserved RNP family domains and selective RNA binding. Science 262:563-566.

Bagni C, Mannucci L, Dotti CG, Amaldi F (2000) Chemical stimulation of synaptosomes modulates alpha- $\mathrm{Ca}^{2+} /$ calmodulin-dependent protein kinase II mRNA association to polysomes. J Neurosci 20:RC76(1-6).

Brown V, Jin P, Ceman S, Darnell JC, O'Donnell WT, Tenenbaum SA, Jin X, Feng Y, Wilkinson KD, Keene JD, Darnell RB, Warren ST (2001) Microarray identification of FMRP-associated brain mRNAs and altered mRNA translational profiles in fragile X syndrome. Cell 107:477-487.

Caudy AA, Myers M, Hannon GJ, Hammond SM (2002) Fragile X-related protein and VIG associate with the RNA interference machinery. Genes Dev 16:2491-2496.

Ceman S, O’Donnell WT, Reed M, Patton S, Pohl J, Warren ST (2003) Phosphorylation influences the translation state of FMRP-associated polyribosomes. Hum Mol Genet 12:3295-3305.

Chapman RE, Walter P (1997) Translational attenuation mediated by an mRNA intron. Curr Biol 7:850-859.

Clark IE, Wyckoff D, Gavis ER (2000) Synthesis of the posterior determinant Nanos is spatially restricted by a novel cotranslational regulatory mechanism. Curr Biol 10:1311-1314.

Corbin F, Bouillon M, Fortin A, Morin S, Rousseau F, Khandjian EW (1997) The fragile $\mathrm{X}$ mental retardation protein is associated with poly $(\mathrm{A})+$ mRNA in actively translating polyribosomes. Hum Mol Genet 6:1465-1472.

Darnell JC, Jensen KB, Jin P, Brown V, Warren ST, Darnell RB (2001) Fragile X mental retardation protein targets $\mathrm{G}$ quartet mRNAs important for neuronal function. Cell 107:489-499.

Davis BD, Tai P-C, Wallacep BJ (1974) Complex interactions of antibiotics with the ribosome. In: Ribosomes (Nomura ATM, Lengyel P, eds), pp 771-789. Cold Spring Harbor, NY: Cold Spring Harbor.

Devys D, Lutz Y, Rouyer N, Bellocq JP, Mandel JL (1993) The FMR-1 protein is cytoplasmic, most abundant in neurons and appears normal in carriers of a fragile X premutation. Nat Genet 4:335-340.

Eberhart DE, Malter HE, Feng Y, Warren ST (1996) The fragile X mental retardation protein is a ribonucleoprotein containing both nuclear localization and nuclear export signals. Hum Mol Genet 5:1083-1091.

Feng Y, Absher D, Eberhart DE, Brown V, Malter HE, Warren ST (1997a) FMRP associates with polyribosomes as an mRNP, and the I304N mutation of severe fragile X syndrome abolishes this association. Mol Cell 1:109-118.

Feng Y, Gutekunst CA, Eberhart DE, Yi H, Warren ST, Hersch SM (1997b) Fragile X mental retardation protein: nucleocytoplasmic shuttling and association with somatodendritic ribosomes. J Neurosci 17:1539-1547.

Huber KM, Gallagher SM, Warren ST, Bear MF (2002) Altered synaptic plasticity in a mouse model of fragile $\mathrm{X}$ mental retardation. Proc Natl Acad Sci USA 99:7746-7750.

Ishizuka A, Siomi MC, Siomi H (2002) A Drosophila fragile X protein interacts with components of RNAi and ribosomal proteins. Genes Dev 16:2497-2508.

Jin P, Warren ST (2003) New insights into fragile X syndrome: from molecules to neurobehaviors. Trends Biochem Sci 28:152-158.

Jin P, Zarnescu DC, Ceman S, Nakamoto M, Mowrey J, Jongens TA, Nelson DL, Moses K, Warren ST (2004) Biochemical and genetic interaction between the fragile X mental retardation protein and the microRNA pathway. Nat Neurosci 7:113-117.

Khandjian EW, Corbin F, Woerly S, Rousseau F (1996) The fragile X mental retardation protein is associated with ribosomes. Nat Genet 12:91-93.

Krichevsky AM, Kosik KS (2001) Neuronal RNA granules: a link between RNA localization and stimulation-dependent translation. Neuron 32:683-696.

Laggerbauer B, Ostareck D, Keidel EM, Ostareck-Lederer A, Fischer U (2001) Evidence that fragile $\mathrm{X}$ mental retardation protein is a negative regulator of translation. Hum Mol Genet 10:329-338.

Li Z, Zhang Y, Ku L, Wilkinson KD, Warren ST, Feng Y (2001) The fragile X mental retardation protein inhibits translation via interacting with mRNA. Nucleic Acids Res 29:2276-2283.

Mazroui R, Huot ME, Tremblay S, Filion C, Labelle Y, Khandjian EW (2002) Trapping of messenger RNA by Fragile X mental retardation protein into cytoplasmic granules induces translation repression. Hum Mol Genet 11:3007-3017.

Miyashiro KY, Beckel-Mitchener A, Purk TP, Becker KG, Barret T, Liu L, Carbonetto S, Weiler IJ, Greenough WT, Eberwine J (2003) RNA cargoes associating with FMRP reveal deficits in cellular functioning in Fmr1 null mice. Neuron 37:417-431.

O’Donnell WT, Warren ST (2002) A decade of molecular studies of fragile X syndrome. Annu Rev Neurosci 25:315-338.

Olsen PH, Ambros V (1999) The lin-4 regulatory RNA controls developmental timing in Caenorhabditis elegans by blocking LIN-14 protein synthesis after the initiation of translation. Dev Biol 216:671-680.

Ramos A, Hollingworth D, Pastore A (2003) G-quartet-dependent recognition between the FMRP RGG box and RNA. RNA 9:1198-1207.

Schaeffer C, Bardoni B, Mandel JL, Ehresmann B, Ehresmann C, Moine H (2001) The fragile X mental retardation protein binds specifically to its mRNA via a purine quartet motif. EMBO J 20:4803-4813.

Seggerson K, Tang L, Moss EG (2002) Two genetic circuits repress the Caenorhabditis elegans heterochronic gene lin-28 after translation initiation. Dev Biol 243:215-225.

Siomi H, Siomi MC, Nussbaum RL, Dreyfuss G (1993) The protein product of the fragile $\mathrm{X}$ gene, FMR1, has characteristics of an RNA-binding protein. Cell 74:291-298.

Todd PK, Mack KJ, Malter JS (2003) The fragile X mental retardation protein is required for type-I metabotropic glutamate receptor-dependent translation of PSD-95. Proc Natl Acad Sci USA 100:14374-14378.

Zalfa F, Giorgi M, Primerano B, Moro A, Di Penta A, Reis S, Oostra B, Bagni C (2003) The fragile X syndrome protein FMRP associates with BC1 RNA and regulates the translation of specific mRNAs at synapses. Cell 112:317-327.

Zhang YQ, Bailey AM, Matthies HJ, Renden RB, Smith MA, Speese SD, Rubin GM, Broadie K (2001) Drosophila fragile X-related gene regulates the MAP1B homolog Futsch to control synaptic structure and function. Cell 107:591-603. 